\title{
On the Activities of the Medullary Extract of the Bovine Adrenal Gland Estimated by Some Biologic Tests, Using the Adrenaline-Noradrenaline Mixture as the Standard
}

\author{
By \\ Tatuzi Suzuki, Toshiyuki Ozaki, Chikamasa Ninagawa and \\ （鈴木 達二）（尾崎俊行）（㵠川 親 正） \\ Teruo Nakamura \\ （中村照夫） \\ From the Department of Physiology, Nagasaki University \\ School of Medicine, Nagasaki
}

(Received for publication, September 14, 1953)

Comparisons of adrenaline estimates of the adrenal extract obtainable by some biologic and chemical tests were performed extensively by Kojima, Nemoto, Saito, Sato and Suzuki. ${ }^{1)}$ Generally speaking, the estimates obtainable by various methods were not identical with each other. This disharmony of adrenaline estimates would be, as was suggested by Kojima et al., due to the presence of some substances allied to adrenaline in the adrenal medulla.

Since L-noradrenaline was recently isolated by Bergström, Euler and Hamberg') as the crystalline base from the adrenal gland of cattle, the presence of noradrenaline in the bovine adrenals together with adrenaline will be unquestionable.

However, it is still uncertain whether active principles other than adrenaline and noradrenaline are contained in the adrenal medulla in a significant amount or not.

Is the fact that the different adrenaline estimates are obtained from the same adrenal extract according to the method applied, as was observed by Kojima et al., wholly due to the presence of noradrenaline along with adrenaline in the adrenal medulla?

To clarify this problem, we have undertaken in the present investigation to compare the activities of the medullary extract of the bovine adrenals in some biologic tests, such as the rabbit intestine segment method, the dog blood pressure and the cat paradoxical pupil reaction, with that of the adrenaline-noradrenaline mixture. 


\section{EXPERIMENTAL}

Methods

The medullary tissue of the bovine adrenals was separated from the cortical tissue and was extracted with $10 \%$ trichloracetic acid. In the first place the extract was assayed chemically in terms of adrenaline and noradrenaline contents by the permanganate method of Suzuki and Ozaki ${ }^{3}$. Then the biologic activities of the extract on the rabbit intestine segment method, the dog blood pressure and the cat denervated iris were estimated, using the adrenaline-noradrenaline mixture as the standard. The adrenaline-noradrenaline mixture was prepared so as to contain just the same percentage of noradrenaline and adrenaline with the chemical estimates of the bovine adrenal extract. L-adrenaline (Sankyo) and Lnoradrenaline-D-bitartrate-monohydrate (Sterling Winthrop) were used. The amount of $\mathrm{L}$-noradrenaline in $10 \mathrm{mg}$. of the latter was taken as $5 \mathrm{mg}$. These were dissolved in $1 / 10 \mathrm{~N}$ hydrochloric acid solution and were stocked in a refrigerator. Just before the tests, these stock solutions were further diluted with physiological saline solution and the mixture was prepared.

It may be needless to say that, if no other active principles than adrenaline and noradrenaline are contained in the adrenal medulla in a significant amount, the activities of the extract estimated by different biologic methods using the adrenaline-noradrenaline mixture as the standard will be similar each other.

The procedure of the biologic tests was wholly the same as was used in our previous investigation."

In the rabbit intestine segment method, the rhythmic movements of the intestine strip in the warmed diluted blood solution were recorded. Then the diluted blood solution containing a known quantity of the extract or the adrenaline-noradrenaline mixture was poured into the intestine chamber to replace the blood solution. Thus the activity of the adrenal extract on the movement of the isolated rabbit intestine segment was compared with that of the adrenaline-noradrenaline mixture.

In the test of the dog blood pressure, the transection of the spinal cord was performed at the lowest level of the cervical segments under ether anesthesia and two or three hours after the section the experiment was started without anesthesia. The diluted solution of the adrenal extract was injected intravenously.

In the tests of the cat denervated iris, the superior cervical ganglion was excised unilaterally under ether one week or more prior to the estimation. At the performance of the test, the animal was anesthetized with urethane. The diluted solution of the adrenaline-noradrenaline mixture or the adrenal extract was injected into the femoral vein. 


\section{Results and Discussion}

With six specimens of the adrenal extracts, the estimations were performed. The results are summarized in Table I.

TAB LE I

Comparison of Activities of the Medullary Extract of the Bovine Adrenals, Estimated by Some Biologic Methods Using the Adrenaline-Noradrenaline Mixture as the Standard

\begin{tabular}{|c|c|c|c|c|c|c|c|}
\hline \multirow{3}{*}{$\begin{array}{l}\text { No. of } \\
\text { extract }\end{array}$} & \multicolumn{4}{|c|}{$\begin{array}{c}\text { Chemical estimates of adrenaline and } \\
\text { noradrenaline content }\end{array}$} & \multirow{2}{*}{\multicolumn{3}{|c|}{$\begin{array}{l}\text { Biologic activities expressed in mg. } \\
\text { equivalents of (adrenaline }+ \\
\text { noradrenaline) per g. of } \\
\text { medullary tissue }\end{array}$}} \\
\hline & \multicolumn{3}{|c|}{ mg. per g. of medullary tissue } & \multirow[b]{2}{*}{ 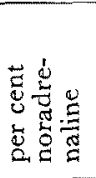 } & & & \\
\hline & $\begin{array}{l}\text { adre- } \\
\text { naline }\end{array}$ & $\begin{array}{l}\text { noradre- } \\
\text { naline }\end{array}$ & $\begin{array}{l}\text { adrenaline } \\
+ \text { nor- } \\
\text { adrenaline }\end{array}$ & & $\begin{array}{l}\text { rabbit intest- } \\
\text { ine segment } \\
\text { method }\end{array}$ & $\begin{array}{c}\text { dog } \\
\text { blood } \\
\text { pressure }\end{array}$ & $\begin{array}{l}\text { cat parado- } \\
\text { xical pupil } \\
\text { reaction }\end{array}$ \\
\hline 1 & 6.7 & 2.6 & 9.3 & 28 & 11.9 & 11.1 & 9.9 \\
\hline 2 & 5.4 & 3.2 & 8.6 & 37 & 11.3 & 9.1 & 10.1 \\
\hline 3 & 8.6 & 3.6 & 12.2 & 30 & 12.8 & 13.6 & 14.7 \\
\hline 4 & 8.5 & 3.5 & 12.0 & 29 & 17.0 & 11.3 & 15.8 \\
\hline 5 & 7.6 & 3.0 & 10.6 & 28 & 10.4 & 10.4 & 12.4 \\
\hline 6 & 6.2 & 3.2 & 9.4 & 34 & 11.1 & 11.1 & 11.1 \\
\hline Mean & 7.2 & 3.2 & 10.4 & 31 & 12.5 & 11.2 & 12.4 \\
\hline
\end{tabular}

Using the permanganate method of Suzuki and Ozaki, the noradrenaline was found to be contained $28-37 \%$ of the total active principles. The sum of the adrenaline and noradrenaline content estimated with this chemical method was $8.6-12.2 \mathrm{mg}$. per g. of the medullary tissue and the average value was $10.4 \mathrm{mg}$.

Using the adrenaline-noradrenaline mixture as the standard, the sum of adrenaline and noradrenaline content was estimated by the rabbit intestine segment method, the dog blood pressure method and the cat paradoxical pupil reaction. The rabbit intestine segment method and the cat pupil method yielded almost similar value, i.e. $12.5 \mathrm{mg}$. and $12.4 \mathrm{mg}$., respectively. The dog blood pressure method gave somewhat smaller value, i.e. $11.2 \mathrm{mg}$. If we compare the estimates obtained by three methods case by case, it will be noticed that the differences of values are rather small in all cases and may be accounted for by errors inherent to the methods tested, except for the extract No. 4.

From the experimental results above presented, it is justifialbe to assume that the difference of the adrenaline estimates observed by Kojima et al. may be in the most of the cases due to the presence of noradrenaline together with adrenaline in the adrenal medullary extract.

Of the extract No. 4, peculiar values were obtained. In this case the 
estimates obtainable by the rabbit intestine segment method and by the cat pupil method were $17.0 \mathrm{mg}$. and $15.8 \mathrm{mg}$., respectively, and were definitely larger than that given by the dog blood pressure method. The latter was $11.3 \mathrm{mg}$.

As the activity ratio of noradrenaline to adrenaline is the highest in the rabbit intestine segment method, the smallest in the cat paradoxical pupil reaction and the intermediate in the dog blood pressure, ${ }^{4)}$ the result obtained with the extract No. 4 can not be explained by the presence of simply two hormones in the adrenal medulla, i.e. adrenaline and noradrenaline.

In examining the experimental results of Kojima et al. concerning the adrenaline estimates of the bovine adrenal medullary tissue case by case, we were surprised to find that in Exps. No. 3 and No. 9 the ratios of the estimates obtainable by the three biologic methods were much the same as that in the extract No. 4 of the present investigation. In Exp. No. 3 of Kojima et al., the adrenaline estimates obtained by the intestine segment method and the pupil method were $11.3 \mathrm{mg}$. and $11.2 \mathrm{mg}$., respectively, and that yielded by the blood pressure method was $7.4 \mathrm{mg}$. In Exp. No. 9, the estimate of adrenaline given by the intestine as well as by the pupil was $14.8 \mathrm{mg}$. and that yielded by the blood pressure was $9.6 \mathrm{mg}$. However, the standard solutions used in the experiments of Kojima et al. and of the present investigation are not the same. Adrenaline solution was used in the former and the adrenaline-noradrenaline mixture in the latter.

\section{SUMMARY}

The present investigation was designed with the desire to know whether the active principles other than adrenaline and noradrenaline are presented in the adrenal medulla in a significant amount or not.

The medullary tissue of the bovine adrenal gland was extracted with trichloracetic acid. At first, the noradrenaline and adrenaline contents were estimated chemically by means of the permanganate method reported by Suzuki and Ozaki. The adrenaline-noradrenaline mixture was then prepared so as to contain just the same percentage of noradrenaline and adrenaline as the chemical estimates of the extract. Using this mixture as the standard the activity of the extract in three biologic tests was estimated quantitatively.

In five out of six specimens, the estimates obtainable by the three different methods were in every case almost similar each other. In one specimen, however, the estimate given by the blood pressure method was definitely smaller than those given by the intestine segment method and the pupil method. 
Thus it can not yet be concluded that the active principles of the adrenal medulla are always soley two hormones, i.e. adrenaline and noradrenaline.

\section{References}

1) Kojima, Nemoto, Saito, Sato, \& Suzuki, Tohoku J. Exp. Med., 1932, 19, 205.

2) Bergström, Euler, \& Hamberg, Acta chem. scand., 1949, 3, 305. Acta physiol. scand., $1950,20,101$.

3) Suzuki, \& Ozaki, Tohoku J. Exp. Med., 1951, 54, 332.

4) Suzuki, Nakamura, \& Ninagawa, Jap. J. Physiol., 1953, 3, 170. 